Physical characteristics. Leaf and pedicel

\title{
Physical and Chemical Characteristics of Pomegranates
}

\author{
Pavlina D. Drogoudi ${ }^{1}$ and Constantinos Tsipouridis \\ Pomology Institute, National Agricultural Research Foundation, P.O. Box \\ 122, R.R. Naoussas 36, Naoussa 59200, Greece
}

\author{
Zisis Michailidis ${ }^{2}$ \\ Technological Educational Institute of Thessaloniki, PO Box 14561, \\ Thessaloniki 54101, Greece
}

Additional index words. antioxidant activity, ascorbic acid, frost resistance, fruit and seed color, total anthocyanins, total phenolics

\begin{abstract}
Twenty pomegranate (Punica granatum L.) accessions were collected from different regions in northern Greece and evaluated under uniform conditions for leaf dimensions, frost resistance, and fruit physical and chemical characteristics, such as the juice antioxidant activity [ascorbate equivalent antioxidant activity (AEAC)], using the radical DPPH, ascorbic acid, total phenolic and total anthocyanin contents. Considerable variation in the characteristics studied was found and valuable pomological traits were exhibited. Cluster analysis produced cases of homonymy between some accessions. Principal component analyses showed that the component explaining the greatest variability positively correlated with percent juice, fruit chroma, AEAC, total anthocyanins, and soluble solids content (SSC), but negatively correlated with fruit fresh weight (FW), fruit and seed hue angle (less red color), total acidity, and leaf dimensions. Fruit size was positively correlated with acidity, while acidity was negatively correlated with SSC. Skin thickness and FW were correlated with fruit hue angle and chroma, suggesting that red color may better develop in thick-skinned and/or small-sized pomegranates. Total anthocyanin content was negatively correlated with $\mathrm{FW}$ and fruit hue angle. AEAC was positively correlated with total anthocyanin and ascorbic acid contents, the latter one constituted a $15 \%$ contribution to AEAC. The associations found among physical and chemical traits suggest that consumers interested in a healthier produce should be directed to small and red pomegranates.
\end{abstract}

The pomegranate (Punica granatum L.) fruit deserves special attention by consumers interested in consuming nutritional food with excellent taste. Dietary supplementation with pomegranate is believed to relate with cancer prevention (Afaq et al., 2003), LDL oxidation and atherosclerosis (Aviram, 2002), and improvement of menopausal syndromes (Mori-Okamoto et al., 2004). Its beneficial effects may be related with its high antioxidant activity, resulting from the presence of a variety of biologically active compounds (Aviram, 2002; Halvorsen et al., 2002). Studies have not been done to determine whether great variability exists in the antioxidant activity among different pomegranate genotypes. This would allow breeders to select and breed genotypes with higher levels of compounds and also provide a way of increasing the dietary intake of antioxidant compounds. Information on the possible relationships between fruit characteristics, such as color, fresh weight, skin thickness etc, with juice chemical characteristics, such as the antioxidant activity, would provide useful information for addressing consumer choices for healthier produce.

Evaluations in pomegranate physical and chemical properties in local material have been

Received for publication 29 Nov. 2004. Accepted for publication $16 \mathrm{Feb} .2005$.

${ }^{1}$ To whom reprint requests should be addressed; e-mail pdrogoudi@alfanet.gr. made in Italy (Barone et al., 2001), Tunisia (Mars and Marrakchi, 1999), and Turkey (Ozkan, 2003), where genotypes selected from Greece were also evaluated (Ozguven et al., 1997). In Greece, pomegranate is spread mainly as a minor fruit, and traditional plantations use local varieties. Recently, its culture increased considerably and is of significant importance to evaluate and conserve local genetic material.

The present study describes the variation among 20 pomegranate accessions selected from different areas in northern Greece and grown under uniform conditions. The objectives of the present study were to a) determine the variability in the juice antioxidant activity and other chemical properties and find whether associations exist between fruit physical and chemical properties, b) determine the overall degree of polymorphism in the characteristics studied, and c) describe and detect similarities in the local material.

\section{Materials and Methods}

Plant material. Twenty pomegranate accessions were collected from various areas in northern Greece and maintained in a collection at the Pomology Institute, Naoussa, Greece. The trees were 5 years old and planted at a 5 $\times 1.5 \mathrm{~m}$ distance in a randomized block design of six trees per genotype in two replicate trees per block. length and leaf width of 50 fully expanded leaves randomly chosen from the tree were measured. Fruit were harvested when most of their color was red and transferred to the laboratory and sorted for size and uniformity of shape. Fruit were hand cracked and the visual appearance of fruit and seed (aril) were evaluated by a 15 -member untrained panel. The 10 best accessions were scored on a 10point hedonic scale $(1=$ poor, $10=$ best $)$ and remaining ten accessions were scored zero. Thickness of skin at equatorial area, fruit fresh weight (FW), and seed and tegmen weight of six-fruit replications were measured. The fruit and seed color $\mathrm{L}^{*}, \mathrm{a}^{*}$, and $\mathrm{b}^{*}$ dimensions were measured using a chromatometer (Minolta, Ramsey, N.J.), and the hue angle $\left(0^{\circ}=\right.$ red-purple; $90^{\circ}=$ yellow $)$ and chroma (departure from gray toward pure chromatic color) parameters were calculated according to McGuire (1992).

A severe frost took place on 8 Apr. 2003 (with temperature reaching $-7{ }^{\circ} \mathrm{C}$ ) and provided the opportunity to assess the ability of genotypes to withstand low temperatures. The percentage of damaged stems was assessed.

Chemical analyses. At harvest, soluble solid content (SSC) and total acidity (TA) were determined in juice extracted using a food processor from a three fruit samples per accession. SSC was measured using a digital refractometer (model PR-1, Atago, Japan) and TA by titration to $\mathrm{pH} 8.2$ with $0.1 \mathrm{~N} \mathrm{NaOH}$ and expressed as citric acid content $(\mathrm{g} / 100 \mathrm{~mL})$.

Upon harvest, six fruit per genotype were frozen at $-20{ }^{\circ} \mathrm{C}$ and chemical analyses were performed within a 3 -month period. Frozen fruit were divided into two halves using a hammer, and intact arils were hand separated and used for analyses or where required juice was extracted using a pestle and mortar.

Chemicals were purchased from Sigma Chemical Co. (St. Louis, Mo.). Assays were performed using an automated UV-visible spectrophotometer.

Antioxidant activity assay. Antioxidant activity in readily extracted juice from frozen fruit was determined using the stable 1,1-diphenyl-2-picryl hydrazyl (DPPH) free radical (Blios, 1958), which has an intense violet color but turns colorless as unpaired electrons are sequestered by antioxidants. Reaction mixtures containing 0 or $20 \mu \mathrm{L}$ diluted juice (1:5 in $\mathrm{MeOH}$ ) and $2980 \mu \mathrm{L}$ of $106.5 \mu \mathrm{M}$ $\mathrm{DPPH}$ in $\mathrm{MeOH}$ were vortexed and then held at room temperature for $4 \mathrm{~h}$. The absorbance of the reaction mixtures was measured at 517 $\mathrm{nm}$, and AEAC (mM) was extrapolated from a standard curve prepared using 0 to $2.7 \mathrm{mM}$ ascorbate $(\mathrm{ASC})\left(\mathrm{y}=(\mathrm{x}+5.836) / 15.816 ; r^{2}=\right.$ 0.999; $P<0.001)$.

Total anthocyanin assay. In total, $200 \mu \mathrm{L}$ of readily extracted juice from frozen fruit, was diluted in $5 \mathrm{~mL} 99 \mathrm{MeOH}$ : $1 \mathrm{HCL}$ and stored for $24 \mathrm{~h}$ in the dark, when absorbance was measured at $530 \mathrm{~nm}$. Results were expressed as mmoles of cyanidine-3-glucoside per 100 mLjuice, using a molar extinction coefficient of 29.600 .

Total phenolic assay. Total soluble pheno- 
Table 1. Mean values of $\%$ frost damage, leaf length, visual scoring and fruit physical properties of 20 pomegranate accessions.

\begin{tabular}{|c|c|c|c|c|c|c|c|c|c|c|c|c|}
\hline $\begin{array}{l}\text { Accession } \\
\text { no. }\end{array}$ & $\begin{array}{c}\text { Frost } \\
\text { damage } \\
(\%)\end{array}$ & $\begin{array}{c}\text { Leaf } \\
\text { length } \\
(\mathrm{mm})\end{array}$ & $\begin{array}{c}\text { Visual } \\
\text { scoring }\end{array}$ & $\begin{array}{l}\text { Fruit } \\
\text { fresh } \\
\text { wt }(g)\end{array}$ & $\begin{array}{c}\text { Seed } \\
\text { wt } \\
(\mathrm{g})\end{array}$ & $\begin{array}{c}\text { Tegmen } \\
\text { wt } \\
(\mathrm{g})\end{array}$ & $\begin{array}{c}\text { Skin } \\
\text { thickness } \\
(\mathrm{mm})\end{array}$ & $\begin{array}{c}\text { Juice } \\
(\%)\end{array}$ & $\begin{array}{l}\text { Fruit } \\
\text { hue }^{\circ}\end{array}$ & $\begin{array}{c}\text { Fruit } \\
\text { chroma }\end{array}$ & $\begin{array}{l}\text { Seed } \\
\text { hue }^{\circ}\end{array}$ & $\begin{array}{c}\text { Seed } \\
\text { chroma }\end{array}$ \\
\hline 11002 & 83.3 & 5.0 & 0.3 & 267.2 & 0.304 & 0.064 & 3.5 & 33.0 & 77.6 & 41.7 & 29.7 & 19.4 \\
\hline 11003 & 100.0 & 6.4 & 0.2 & 284.5 & 0.180 & 0.068 & 4.0 & 36.6 & 60.5 & 40.2 & 27.6 & 22.2 \\
\hline 11005 & 75.0 & 5.0 & 6.3 & 333.3 & 0.208 & 0.056 & 3.0 & 29.8 & 65.6 & 44.1 & 32.5 & 24.8 \\
\hline 11006 & 79.0 & 6.9 & 15.9 & 445.1 & 0.332 & 0.088 & 4.0 & 26.8 & 68.8 & 42.2 & 48.8 & 21.5 \\
\hline 11009 & 43.8 & 6.1 & 11.5 & 271.3 & 0.208 & 0.064 & 6.3 & 31.9 & 36.8 & 52.6 & 30.1 & 17.1 \\
\hline 11010 & 33.3 & 5.1 & 9.9 & 245.5 & 0.268 & 0.060 & 7.0 & 32.1 & 33.8 & 49.6 & 37.2 & 22.6 \\
\hline 11011 & 83.3 & 6.6 & 7.3 & 394.2 & 0.292 & 0.064 & 4.0 & 30.6 & 65.0 & 45.4 & 29.7 & 18.9 \\
\hline 11012 & 100.0 & 3.7 & 1.7 & 293.2 & 0.308 & 0.068 & 7.0 & 35.7 & 42.4 & 50.2 & 31.7 & 15.6 \\
\hline 11014 & 98.3 & 4.0 & 0.7 & 310.8 & 0.292 & 0.052 & 6.0 & 32.6 & 32.0 & 48.4 & 25.3 & 17.2 \\
\hline 11015 & 84.0 & 3.7 & 7.2 & 273.0 & 0.324 & 0.072 & 7.0 & 31.4 & 34.2 & 48.7 & 31.3 & 15.0 \\
\hline 11016 & 52.1 & 4.3 & 4.6 & 344.2 & 0.260 & 0.048 & 4.0 & 35.8 & 40.2 & 44.9 & 26.7 & 15.5 \\
\hline 11018 & 90.3 & 4.9 & 0.9 & 303.5 & 0.371 & 0.090 & 4.2 & 33.7 & 60.2 & 46.1 & 28.5 & 12.0 \\
\hline 11019 & 100.0 & 5.0 & 1.7 & 301.7 & 0.360 & 0.064 & 7.0 & 34.1 & 61.8 & 47.7 & 29.7 & 16.0 \\
\hline 11020 & 87.5 & 4.6 & 1.4 & 315.7 & 0.344 & 0.072 & 5.5 & 34.5 & 30.4 & 49.0 & 30.0 & 20.7 \\
\hline 11021 & 75.0 & 5.1 & 4.9 & 351.6 & 0.360 & 0.092 & 5.0 & 30.5 & 88.8 & 43.0 & 28.1 & 17.4 \\
\hline 11022 & 82.5 & 5.6 & 2.1 & 386.3 & 0.192 & 0.048 & 5.0 & 30.6 & 67.3 & 40.4 & 29.2 & 16.1 \\
\hline 11025 & 59.6 & 5.5 & 7.3 & 342.8 & 0.228 & 0.060 & 3.0 & 31.0 & 54.9 & 42.2 & 34.2 & 25.0 \\
\hline 11026 & 50.7 & 3.2 & 4.4 & 350.8 & 0.375 & 0.095 & 4.6 & 34.4 & 57.9 & 48.8 & 25.9 & 18.8 \\
\hline 11029 & 62.5 & 5.4 & 3.2 & 351.5 & 0.320 & 0.090 & 4.5 & 32.3 & 86.8 & 43.4 & 31.0 & 21.0 \\
\hline 11041 & 33.8 & 4.4 & 6.9 & 402.6 & 0.300 & 0.070 & 4.4 & 29.3 & 64.2 & 42.3 & 32.3 & 25.3 \\
\hline$P$ & $23.0^{z}$ & $<0.001$ & $<0.001$ & 0.020 & $<0.001$ & $<0.001$ & $<0.001$ & $0.375^{z}$ & $<0.001$ & 0.001 & 0.060 & 0.485 \\
\hline LSD & --- & 0.2 & 4.3 & 39.2 & 0.06 & 0.01 & 0.6 & --- & 25.0 & 5.8 & --- & --- \\
\hline
\end{tabular}

${ }^{\mathrm{z}} \mathrm{LSD}$ calculated for arcsine transformed values.

Table 2. Mean values of antioxidant activity [ascorbate equivalent antioxidant capacity (AEAC)] and ascorbic acid, total anthocyanin, total phenolic, soluble solid (SSC), and total acid (TA) contents in 20 pomegranate accessions.

\begin{tabular}{|c|c|c|c|c|c|c|}
\hline $\begin{array}{l}\text { Accession } \\
\text { no. }\end{array}$ & $\begin{array}{l}\text { AEAC } \\
(\mathrm{mM})\end{array}$ & $\begin{array}{c}\text { Ascorbic acid } \\
(\mathrm{mg} / 100 \mathrm{~mL})\end{array}$ & $\begin{array}{c}\text { Total anthocyanins } \\
(\mathrm{mmol} / 100 \mathrm{~mL})\end{array}$ & $\begin{array}{l}\text { Total phenolics } \\
(\mathrm{mg} / 100 \mathrm{~mL})\end{array}$ & $\begin{array}{l}\mathrm{SSC} \\
(\%)\end{array}$ & $\begin{array}{c}\text { TA } \\
(\mathrm{g} / 100 \mathrm{~mL})\end{array}$ \\
\hline 11002 & 19.7 & 4.3 & 62.3 & 44.5 & 15.0 & 0.349 \\
\hline 11003 & 16.5 & 2.6 & 65.4 & 47.7 & 16.5 & 0.314 \\
\hline 11005 & 16.2 & 4.8 & 61.6 & 44.8 & 15.3 & 0.314 \\
\hline 11006 & 12.1 & 1.7 & 49.9 & 44.2 & 14.7 & 2.050 \\
\hline 11009 & 15.9 & 2.7 & 63.0 & 48.0 & 15.8 & 0.406 \\
\hline 11010 & 17.0 & 2.5 & 64.8 & 55.1 & 14.8 & 0.467 \\
\hline 11011 & 15.4 & 1.3 & 58.3 & 47.4 & 15.0 & 2.001 \\
\hline 11012 & 18.5 & 2.8 & 55.1 & 49.0 & 16.7 & 0.338 \\
\hline 11014 & 17.5 & 1.9 & 67.4 & 53.6 & 15.9 & 0.378 \\
\hline 11015 & 17.4 & 2.1 & 66.4 & 41.3 & 15.9 & 0.360 \\
\hline 11016 & 18.8 & 2.3 & 62.6 & 43.7 & 16.8 & 0.417 \\
\hline 11018 & 16.0 & 3.8 & 66.3 & 49.5 & 16.1 & 0.330 \\
\hline 11019 & 18.5 & 3.1 & 68.5 & 69.7 & 16.5 & 0.341 \\
\hline 11020 & 17.3 & 3.1 & 72.4 & 64.8 & 16.9 & 0.361 \\
\hline 11021 & 14.6 & 1.7 & 63.4 & 52.7 & 15.8 & 0.525 \\
\hline 11022 & 17.8 & 1.6 & 50.7 & 42.2 & 15.2 & 1.104 \\
\hline 11025 & 17.4 & 2.6 & 61.4 & 42.4 & 14.8 & 2.168 \\
\hline 11026 & 25.0 & 5.2 & 64.0 & 40.7 & 17.0 & 0.401 \\
\hline 11029 & 10.0 & 2.0 & 42.7 & 22.5 & 14.4 & 0.212 \\
\hline 11041 & 16.8 & 2.0 & 53.4 & 27.3 & 14.8 & 2.392 \\
\hline$P$ & $<0.001$ & 0.001 & $<0.001$ & 0.110 & 0.495 & $<0.001$ \\
\hline LSD & 2.10 & 1.40 & 7.50 & --- & --- & 0.62 \\
\hline
\end{tabular}

Table 3. Variables selected with factor loadings and explained cumulated proportion of variation for the first three eigenvectors.

\begin{tabular}{|c|c|c|c|}
\hline Characteristic & $\begin{array}{c}\text { Factor } 1 \\
(37.3)\end{array}$ & $\begin{array}{c}\text { Factor } 2 \\
(50.3)\end{array}$ & $\begin{array}{c}\text { Factor } 3 \\
(61.2)\end{array}$ \\
\hline Percent frost damage & 0.304 & 0.416 & 0.290 \\
\hline Leaf length & -0.739 & 0.553 & 0.019 \\
\hline Leaf blade length & -0.724 & 0.583 & 0.023 \\
\hline Leaf blade width & -0.692 & 0.433 & 0.247 \\
\hline Fruit fresh weight & -0.689 & -0.309 & 0.206 \\
\hline Seed weight & 0.260 & -0.365 & 0.821 \\
\hline Tegmen weight & -0.056 & -0.406 & 0.758 \\
\hline Skin thickness & 0.546 & 0.369 & 0.286 \\
\hline Percent juice & 0.738 & 0.122 & -0.103 \\
\hline Fruit hue $^{\circ}$ & -0.593 & -0.346 & 0.278 \\
\hline Fruit chroma & 0.669 & 0.197 & 0.167 \\
\hline Seed hue $^{\circ}$ & -0.616 & 0.160 & 0.227 \\
\hline Seed chroma & -0.534 & -0.155 & -0.437 \\
\hline Ascorbate equivalent antioxidant activity & 0.670 & -0.306 & -0.290 \\
\hline Ascorbic acid & 0.455 & -0.387 & -0.151 \\
\hline Total anthocyanins & 0.719 & 0.260 & -0.064 \\
\hline Total phenolics & 0.502 & 0.620 & 0.223 \\
\hline Soluble solids & 0.817 & 0.058 & 0.132 \\
\hline Total acids & -0.710 & -0.120 & -0.075 \\
\hline
\end{tabular}

lics were determined with the Folin-Ciocalteu reagent and results were expressed as $\mathrm{mg}$ gallic acid/ $100 \mathrm{~mL}$.

Ascorbic acid assay. Seeds (about $0.8 \mathrm{~g}$ ) were extracted in $1 \mathrm{~mL}$ of ice-cold $6 \%(\mathrm{w} / \mathrm{v})$ metaphosphoric acid containing $0.2 \mathrm{mMDTPA}$. The tegmens were removed, towel dried, and weighed. The extract was centrifuged at $10,000 \mathrm{~g}_{\mathrm{n}}$ for $4 \mathrm{~min}$ at $4{ }^{\circ} \mathrm{C}$ and the supernatant recovered. ASC was measured using the spectrophotometric method described by Takahama and Oniki (1992). The reaction mixture contained a $50-\mu \mathrm{L}$ aliquot of extract in $60 \mathrm{~mm}$ potassium phosphate buffer ( $\mathrm{pH} 6.3$ ), and the difference in absorbance at $265 \mathrm{~nm}$ was measured before and $2 \mathrm{~min}$ after the addition of ascorbate oxidase $(1 \mathrm{U} / \mathrm{mL})$. Results were expressed as $\mathrm{mg} \mathrm{ASC} / 100 \mathrm{~mL}$.

Statistical analysis. Analysis of variance, correlation analysis, principal component 
Table 4. Correlation matrix of pomegranate physical and chemical characteristics. Absolute linear correlation $\geq|0.50|$ are marked in bold.

\begin{tabular}{|c|c|c|c|c|c|c|c|c|c|c|c|c|c|c|c|c|}
\hline Parameter & 1 & 2 & 3 & 4 & 5 & 6 & 7 & 8 & 9 & 10 & 11 & 12 & 13 & 14 & 15 & 16 \\
\hline 1. Leaf length & 1 & & & & & & & & & & & & & & & \\
\hline 2. Fruit fresh weight & NS & 1 & & & & & & & & & & & & & & \\
\hline 3. Seed weight & NS & NS & 1 & & & & & & & & & & & & & \\
\hline 4. Tegmen weight & NS & NS & 0.702 & 1 & & & & & & & & & & & & \\
\hline 5. Skin thickness & NS & -0.487 & NS & NS & 1 & & & & & & & & & & & \\
\hline 6. Percent juice & NS & -0.590 & NS & NS & NS & 1 & & & & & & & & & & \\
\hline 7. Fruit hue & NS & 0.468 & NS & NS & -0.543 & NS & 1 & & & & & & & & & \\
\hline 8. Fruit chroma & NS & -0.509 & NS & NS & 0.730 & NS & -0.713 & 1 & & & & & & & & \\
\hline 9. Seed hue & 0.448 & NS & NS & NS & NS & -0.633 & NS & NS & 1 & & & & & & & \\
\hline 10. Seed chroma & NS & NS & NS & NS & -0.445 & NS & NS & NS & NS & 1 & & & & & & \\
\hline 11. Ascorbate equivalent antioxidant activity & -0.613 & NS & NS & NS & NS & 0.463 & NS & NS & -0.459 & NS & 1 & & & & & \\
\hline 12. Ascorbic acid & NS & NS & NS & NS & NS & NS & NS & NS & NS & NS & 0.577 & 1 & & & & \\
\hline 13. Total anthocyanin & NS & -0.599 & NS & NS & NS & 0.450 & -0.539 & 0.444 & NS & NS & 0.513 & NS & 1 & & & \\
\hline 14. Total phenolics & NS & NS & NS & NS & NS & NS & NS & NS & NS & NS & NS & NS & 0.742 & 1 & & \\
\hline 15. Soluble solids content & -0.503 & NS & NS & NS & NS & 0.762 & -0.445 & 0.450 & -0.539 & -0.511 & 0.586 & NS & 0.618 & 0.511 & 1 & \\
\hline 16. Total acids & NS & 0.717 & NS & NS & NS & -0.649 & NS & NS & 0.493 & 0.465 & NS & NS & NS & NS & -0.548 & 1 \\
\hline
\end{tabular}

Clusters

$\begin{array}{lrrrr}0 & 5 & 10 & 15 & 20\end{array}$

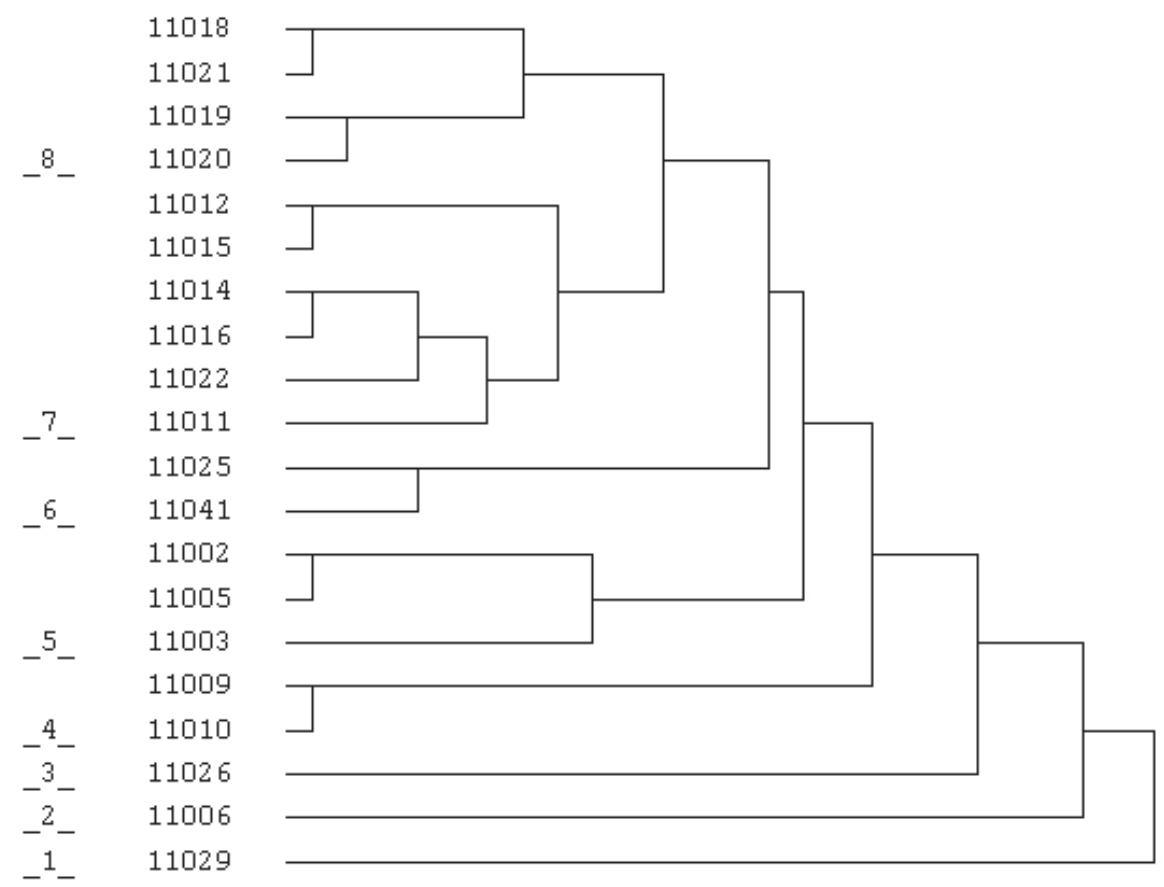

Fig. 1. Cluster dendrogram of 20 Greek pomegranate accessions.

analysis (PCA), and between-group linkage cluster analysis using the method of squared Euclidean distance, were performed using SPSS (Chicago, Ill.). Percentage data were arcsine transformed before analysis. LSD values were calculated in cases that significance at $P \leq 0.05$ variance was found among accessions.

\section{Results and Discussion}

Great variation in the percentage frost damage, leaf characteristics, and fruit physical and chemical traits of the pomegranate accessions was found (Tables 1 and 2). AEAC varied 2-fold, with accessions 11002 and 11026 containing the greatest amounts of antioxidant compounds, which is useful information for breeders and nutritionists. Total phenolics varied between 22.5 and $69.7 \mathrm{mg} / 100 \mathrm{~mL}$ and anthocyanins between 42.7 and $72.4 \mathrm{mmol} / 100$ $\mathrm{mL}$. Ascorbic acid content was between 1.3 and $5.2 \mathrm{mg} / 100 \mathrm{~mL}$, values slightly greater than 0.4 to $2.2 \mathrm{mg} / 100 \mathrm{~mL}$ reported by Al-Khatani (1992), probably attributed to genotypic differences and/or different analyses methods used, particularly since ascorbic acid oxidation is fast in readily extracted juice (Marti et al., 2001).

Differences in frost resistance were found, the percentage stem injury ranging between $33.3 \%$ and $100.0 \%$, suggesting that some accessions (11009, 11010, 11016, 11025, and 11041) could be suitable for growing in frost susceptible areas. From the results of fruit and seed visual evaluation, popular accessions intense red color. Large pomegranate acceswere 11009,11010 , and 11015 due to a very sions $(11006,11011,11025$, and 11041) were also popular but they were all sour varieties (TA $>1.8 \%$ ), according to Evreinoff classification (1957).

PCA was applied to mean values of measured traits for detecting the most important factors of variability and to describe the relationship between variables and observations (Table 3). The interdependence of the variables was investigated by analysis of correlation (Table 4). PCA produced three components accounted for a cumulative $61.2 \%$ of variation; the most important variables integrated by the first component (37.3\% of variance) were percent juice, fruit chroma, AEAC, total anthocyanins, and SSC, while negative correlation had leaf dimensions, FW, seed hue angle, and TA. The second component (13.0\% of variance) was mainly correlated with percent frost damage, leaf dimensions, and total phenolics, while negative correlation had tegmen weight. The seed and tegmen weights were the most important variables of the third component $(10.9 \%$ of variance) and were highly correlated $(r=0.702)$. Most measured traits had high discriminating values, while it is interesting that some of the consumers' most perceivable fruit characters such as fruit and seed hue color and FW had an opposite relationship with juice antioxidant properties. Traits related to fruit size and color, and juice (color, SSC, TA, and $\mathrm{pH}$ ) characteristics, but no sepal number and calyx dimensions, had similarly high discriminating values when 30 Tunisian pomegranate accessions were evaluated (Mars and Marrakchi, 1999).

Although large pomegranates are more appealing to the consumer, these are more likely to be acidic. This was suggested by the positive correlation between fruit weight and TA $(r=0.717)$, while the fruit and seed visual evaluation showed that the most popular were large but also acidic pomegranates. SSC was negatively correlated with TA $(r=-0.632)$, and similarly Melgarejo etal. (2000) found that sour pomegranate contain more TA and less SSC than sour-sweet and sweet pomegranates.

Skin thickness and FW were correlated with fruit hue $(r=-0.543$ and 0.468 , respectively) and fruit chroma ( $r=0.730$ and $r=-0.509$, respectively) suggesting that red color (low hue ${ }^{\circ}$ and high chroma values) may better develop in thick-skinned and/or small 
pomegranates. Moreover, FW was negatively correlated with percent juice $(r=-0.590)$, suggesting that small fruit may be better for juice purposes. Similarly, Jalikop and Kumar (1998) reported that small fruit are juicier as well as soft-seeded. No significant correlations were found among fruit and seed color parameters, suggesting that external color does not reflect internal color.

Regarding the juice antioxidant characteristics, total anthocyanin content was negatively correlated with FW $(r=-0.599)$ and fruit-hue $(r=-0.539)$, suggesting that small and /or red fruit contain more anthocyanins in juice. AEAC was positively correlated with SSC $(r=0.586)$ and negatively with leaf length $(r=-0.613)$. Total phenolic and anthocyanin content were positively correlated $(r=0.742)$, while AEAC was correlated with total anthocyanin $(r=$ 0.513 ) but not total phenolic content. Gil et al. (2000) found that the phenolic punicalagin is the most potent antioxidant found in pomegranate juice, but that anthocyanins also contributed to total antioxidant capacity of the juice. AEAC was also significantly correlated with ASC ( $r=$ $0.577)$, a potent antioxidant, but constitutes a relatively low $(15 \%)$ contribution to AEAC in pomegranate, being similar to values reported for other fruit (Wang et al., 1996).

Cluster analysis produced eight clusters showing cases of homonymy (low dissimilarity levels) between accessions 11018 and 11021 , 11019 and 11020, 11012 and 11015, 11014 and 11016,11002 and 11005 , and 11009 and 11010 , indicating that a close relationship, or synonymy, between those accessions exist (Fig. 1). High dissimilarity level was found in accessions 11026, 11006, and 11029, being highly heterogeneous among the rest studied accessions. The studied accessions were only selected from the northern part of Greece and probably constitute a portion of the indigenous germplasm. Further evaluations as well as hybridization within accessions with favorable traits from an agronomic and nutritional perspective would be necessary for evolving new varieties.

\section{Literature Cited}

Afaq, F., M. Saleem, and H. Mukhtar. 2003. Pomegranate fruit extract is a novel agent for cancer chemoprevention: Studies in mouse skin. 2nd Annual AACR Int. Conf. on Frontiers in Cancer Prevention Res., 26-30 Oct., Cancer Epidem. Biomar. 12:1351S-1351S Part 2 Suppl. S.

Al-Khatani, H.A. 1992. Intercultivar differences in quality and postharvest life of pomegranate influenced by partial drying. J. Amer. Soc. Hort. Sci. 117:100-104.

Aviram, M. 2002. Pomegranate juice as a major source for polyphenolic flavonoids and it is most potent antioxidant against LDL oxidation and atherosclerosis Free Radical Biol. Med. 33:364 Suppl. 1.

Barone, E., T. Caruso, F.P. Marra, and F. Sottile. 2001. Preliminary observations on some Sicilian pomegranate (Punica granatum L.) varieties. J. Amer. Pomol. Soc. 55:4-7.

Blios, M.S. 1958. Antioxidant determination by the use of stable free radicals. Nature 181:1199-1200

Evreinoff, V.A. 1957. Contribution a l'etude du grenadier. J. Agr. Trop. Bot. Appl. (3/4):124-138.

Gil, M.I., F.A. Tomas-Barberan, B. Hess-Pierce, D.M. Holcroft, and A.A. Kader. 2000. Antioxidant activity of pomegranate juice and its relationship with phenolic composition and processing. J. Agr. Food Chem. 48:4581-4589.

Halvorsen, B.L., K. Holte, M.C.W. Myhrstad, I. Barikmo, E. Hvattum, S.F. Remberg, A.B. Wold, K. Haffner, H. Baugerod, L.F. Andersen, J.O.
Moskaug, D.R. Jacobs, and R. Blomhoff. 2002. A systematic screening of total antioxidants in dietary plants. J. Nutr. 132:461-471.

Jalikop, S.H., and P.S Kumar. 1998. Use of soft, semi-soft- and hard-seeded types of pomegranate (Punica granatum) for improvement of fruit attributes. Indian J. Agr. Sci. 68:87-91.

Mars, M., and M. Marrakchi. 1999. Diversity of pomegranate (Punica granatum L.) germplasm in Tunisia. Genetic resources and crop evolution 46:461-467.

Marti, N, A. Perez-Vicente, and C. Garcia-Viguera. 2001. Influence of storage temperature and ascorbic acid addition on pomegranate juice. J. Sci. Food Agr. 82:217-221.

McGuire, R.G. 1992. Reporting of objective color measurements. HortScience 27:1254-1255.

Melgarejo, P, D.M. Salazar, and F. Artes. 2000. Organic acids and sugars composition of harvested pomegranate fruits. Euro. Food Res. Technol. 211:185-190.

Mori-Okamoto, J, Y. Otawara-Hamamoto, H. Yamato, and H. Yoshimura. 2004. Pomegranate extract improves a depressive state and bone properties in menopausal syndrome model ovariectomized mice. J. Ethnopharmacol. 92:93-101.

Ozguven, A.I., H. Tatli, M. Coskun, and Y. Daskan. 1997. Fruit characteristics of some Mediterranean and Aegean pomegranate varieties under ecological conditions of Adana, Turkey. Acta Hort. 441:345-349.

Ozkan, Y. 2003. Determination of pomological characteristics of Niksar district pomegranates (Punica granatum L.) of the Tokat province. Acta Hort. 598:199-203.

Takahama U. and T. Oniki. 1994. The association of ascorbate and ascorbate oxidase in the apoplast with IAA-enhanced elongation of epicotyls from Vigna angularis. Plant Cell Physiol. 35:257-266.

Wang, H., G.H. Cao, and R.L. Prior. 1996. Total antioxidant capacity of fruits J. Agr. Food Chem. 44:701-705. 